\title{
A caneta que escreve e a que prescreve: literatura e medicina em Portugal
}

\section{A caneta que escreve e a que prescreve: literature and medicine in Portugal}

\section{SUZIE MARRA*}

título $A$ caneta que escreve e a que prescreve (ações em que esse instrumento e símbolo da escrita e da criação literária se reveza harmoniosamente na mesma mão) $)^{2}$ foi inspirado no Diário IX do escritor português Miguel Torga e serve à antologia proposta pela autora Clara Crabbé Rocha como uma luva, uma vez que o livro quer tratar das temáticas da doença e da medicina na literatura portuguesa, conforme aponta o subtítulo da obra. Nela, encontram-se reunidos prosa e verso, num volume em que se agrupam mais de cem autores portugueses, em textos que, de uma forma ou outra, se expressam sobre os diversos aspectos da experiência humana diante das questões contingentes que envolvem a saúde e a doença, colocadas sob pontos de vista tão diferentes quanto a diversidade dessas abordagens. Tendo como pano de fundo esses estados do humano, o par doença-saúde apresenta-se desde a perspectiva do observador mais imparcial à do eu pessoal do médico, explicitando o que poderíamos denominar de uma linhagem literária da medicina dentro da cultura portuguesa. Como afirma a organizadora para revista Norte Médico - publicação da Ordem dos Médicos de Portugal -, "a representação da doença, enquanto expressão de vida, acompanha a nossa literatura [portuguesa] desde os primórdios" (SOARES, 2012, p. 91),

\footnotetext{
* Jornalista e Doutoranda pelo Programa de Estudos Comparados de Literaturas de Língua Portuguesa da FFLCH-USP. Linha de Pesquisa: Literatura e outros saberes.

2 As citações referentes ao livro serão feitas somente com o número da página.
} 
ao que acrescenta que deveríamos realizar mais vezes o ato de "avaliar as pontes entre a cultura científica e a humanística" (SOARES, 2012, p. 91).

É um prazer ler o livro organizado por Clara Rocha. Nele, lêem-se a medicina e os aspectos da saúde e da doença à luz da literatura, mediante um trabalho. inédito em português, de pesquisa e de compilação temático-literárias. São textos que se enredam num tempo histórico que, embora organizado cronologicamente, não se torna protagonista, porque cede seu lugar e espaço à temática. Tal esforço parece corresponder a um interesse particular da autora, que já havia elaborado o assunto, literatura e medicina. numa conferência proferida no Forum Gulbenkian Saúde, intitulada "Medicina e outras Artes". A antologia também responde ao crescente interesse pelos estudos interdisciplinares entre saúde e literatura, fundamentalmente a partir das linhas de pesquisa desenvolvidas no King's College London e na Columbia University (USA) a partir dos anos 2000 e trabalhadas em Portugal pelo grupo Narrative \& Medicine da Faculdade de Letras da Universidade de Lisboa desde 2009.

O prefácio de Emilio Rui Vilar - Doutor Honoris Causa pela Universidade de Lisboa em 2011 - deixa claro que a investigação, feita com a colaboração de Teresa Jorge Ferreira, apresenta os registros (con)textuais variados presentes na antologia, "desde o mais sério, pungente ou trágico até o mais circunstancial, lúdico, anedótico ou mesmo satírico" (VILAR, in ROCHA, 2011, p. 12). São ao todo 365 páginas, como a soma dos dias de um ano, que nos mostram diferentes textos de vários gêneros e subgêneros literários - diário, conto, dramaturgia, ensaio, autobiografias -, escritos em verso e prosa, sob estilos autorais diversos e que abrangem do século XIII ao século XXI. No livro, estão colocados aspectos que vão de receitas para uma boa saúde ou uma vida salutar a questionamentos, sobretudo em relação ao estado de vulnerabilidade da condição humana nas dimensões das disposições da saúde física e moral, expostas por meio das criações literárias apresentadas ali e seus respectivos autores.

Seguindo as categorias propostas por Emilio Rui Vilar, "a origem e o termo da vida, a doença e a dor, o sofrimento físico e moral, a procura da plenitude e do equilíbrio e bem-estar, que se chama saúde" (VILAR, in ROCHA, 2011, p. 12), há autores e obras que cabe, aqui, ressaltar.

Em termos da vida em sua duração e fim, há o interessante relato do Pe. António Vieira ao superior de sua congregação a contar sobre a impertinência dos mosquitos: uma (auto)análise da sua missão junto aos índios e observação 
crítica da consciência dos índios em relação à cobiça dos homens. Tal contar impõe-se como diário com valor de um documento histórico, e não somente relato autobiográfico:

[...] No rio das Amazonas há uma nação que chamam dos Esfolados, por andarem sempre assim por causa dos mosquitos [...]. Das cousas que ficam [contadas], está é a mais custosa que de cá padece [...]. Desta maneira se vai cultivando e plantando esta antiga vinha do Senhor, e no tempo de colher o fruto, que é o da morte, se trabalha muito por que se não perca o que se tem cultivado [...]. Distam as aldeias da cidade, onde temos a nossa casa, a quatro ou a cinco léguas, e, em adoecendo algum índio [...] há ordem para que logo nos chamem, e a qualquer hora do dia ou da noite lhe íamos acudir, de sorte que nenhum índio morre hoje nas aldeias sem sacramentos, como morriam até agora todos. [...] E como essa gente não tem vícios, nem embaraços de consciência [...] o índio que morre com os sacramentos se salva, e assim o mostra a quietação e sossego, e a piedade, com que os vemos morrer. (p.63-64)

Da doença e da dor falam Bocage, por versos satíricos, "A cada penada sua $O$ enfermo arranca um ai. Não se assuste (diz Galeno) Que inda desta si não vai." (p. 85), e João de Araújo Correia, que nos oferece outra perspectiva, ao contar histórias advindas da própria sensibilidade médica. Desse mesmo lugar, escreve o também médico Júlio Dinis - que inicia seu trabalho literário sob o pseudônimo de Diana de Aveleda e que, ao contrário de Camilo Castello Branco, nas palavras de Vitorino Nemésio "suaviza toda a extensão da sua intriga e da sua figuração novelística, deixando, todavia, ao acontecer e às personagens uma verossimilhança amável, uma naturalidade suave, e proba" (p. 130), como por exemplo; o que se lê, sobremaneira, no personagem/médico João Semana (p.102-6).

Outros literatos e médicos que figuram nesse compêndio são: Garcia de Orta, Fialho de Almeida, Jaime Cortesão - salientada a obra 'Memórias da grande Guerra', de onde foi extraído o trecho incluído nesta antologia, escrita com base na sua experiência como capitão-médico (voluntário) do corpo expedicionário português na primeira guerra mundial. Além de, claro, os imprescindíveis António Lobo Antunes, Fernando Namora e Miguel Torga. 
Entre os afeitos à prática jornalística, figuram, por exemplo, os escritores Eça de Queiroz, o também poeta Alexandre Herculano, José Régio - fundador da revista portuguesa Presença, em 1927 - e Fernão Lopes, cronista de D. João I conhecido pela descrição minuciosa que faz dos eventos ocorridos na época (c.1380-c.1459), incluídos registros de testemunhos e diálogos, a serem lidos no capítulo "Da pestelença que andava entre os Castelãos e dalguus capitães que em ela morrerom" (p.24-6). Nessa categoria também se destacam os nomes de Almeida Garrett, Mário-Henrique Leiria, Agustina Bessa Luís e Vitorino Nemésio.

O sofrimento físico e moral é abordado por António Nobre - ele mesmo tendo morrido de tuberculose -, além de por Fernando Pessoa, que, em muitas de suas obras, fala da doença, da dor e, no limite, da questão da "busca de saúde, individual e coletiva" (Perrone- Moisés, p.95), como lemos no trecho do poema que segue:

Há doenças piores que as doenças,

Há dores que não doem, nem na alma,

Mas que são dolorosas mais que as outras.

[...]

Dá-me mais vinho porque a vida é nada. (p. 162)

Alguns textos da antologia seguem pelo viés da crítica apurada daqueles autores que retiram da observação aguda o aspecto formal da sua expressão, tal qual Augusto Abelaira, Nuno Bragança, Maria Isabel Barreno, Mario de Carvalho, Maria Judite de Carvalho, Gonçalo M. Tavares e Pedro Paixão. De acordo com um tipo de sensibilidade que imprime forma ao texto, lemos, em Natalia Correia:

Uma dor fina que o peito me atravessa,

A escuridão que envolve o pensamento,

Um não ter para onde ir cheio de pressa,

Um correr para o nada em passo lento,

[...]

É tédio? É depressão? Talvez loucura?

É, para um além de mim, passagem escura?

Um ir por ir que não tem outro lado? (p. 252) 
José Cardoso Pires, em seu relato autobiográfico a respeito do acidente vascular cerebral que o vitimara, refere-se à plenitude perdida, à sensação de 'desamparo' que isso lhe provoca, e que acaba por determinar uma narrativa apoiada na questão da memória e da identidade: "Espantoso como bruscamente o meu eu se transformou ali noutro alguém, noutro personagem menos imediato e menos concreto" (p. 261), complementado por outro trecho em que fala explicitamente sobre a perda de si: "como se acabasse de dar início a um processo de despersonalização [...] me transferi para um Outro sem nome e sem memória e por consequência incapaz da menor relação passado-presente" (p. 262). Já Eugénio de Andrade, entre esses exemplos de narrativa suprassensível, constrói um monumento em prosa dedicado a Teixeira Pascoaes quando de sua doença e morte: "Queria despegar de mim a imagem do poeta morto. Não é esse o meu Pascoaes" (p. 249). E prossegue: "A sua presença era inquieta e feliz, não deixando nada em sossego, em nome da verdade. A mentira era para ele o maior dos pecados - Eu devo ter me enganado várias vezes, mas nunca menti" (p. 249).

Emociona a escrita de cartas como a "Carta a Wilhelm Storck", de Antero de Quental: “ [...] Nesse mesmo ano de 1874 adoeci gravissimamente, com uma doença nervosa de que nunca mais pude recuperar-me completamente. A forçada inaç̧ão [...] e uma certa acuidade de sentimentos [...] puseram-me novamente e mais imperiosamente do que nunca, em face do grande problema da existência" (p. 107).

Laureado por muitos críticos de Portugal como um dos mais importantes poetas portugueses, senão, considerado por outros, o maior nome depois de Fernando Pessoa, Herberto Helder foi escritor que se valeu de uma linguagem que remete ao corpo como lugar de expressão no texto. Na obra 'Os Passos em Volta', considerada um clássico da literatura portuguesa, a que a antologia remete e na qual o autor se apresenta, de certa forma, introspectivo, inscreve-se a diç̧ão do escritor que parece querer nos mostrar o mais intimo do pensamento em relação à condição humana. No começo, pontua: "Convivia com bastante gente. Claro, não amava ninguém. E, então, vi de súbito a nódoa na mão direita" (p. 277), continuando, "Gosto da mão direita, associo-a porventura à tradição de que é um nobre instrumento da obra, de que se articula com a própria profundidade dos nossos talentos" (p. 277). Para concluir: "Contudo penso que não era, nem é, uma doença física [...] Talvez o meu corpo esteja como dantes, fechado, 
intacto. [...] Talvez entre o amor e o mundo haja uma chaga pior - a memória mortal" (p. 280).

Em A caneta que escreve e a que prescreve, lemos ainda as escritoras Florbela Espanca, Teolinda Gersão e Ana Hatherly: "Qual é a sua profissão? Perguntou um escritor a um crítico. Eu sou médico de palavras. Médico de palavras? Tinha ido cortar o cabelo e achava-se desprovido de argumento (p. 275). Ainda fazem parte da obra textos de Gil Vicente, Raul Brandão, Cesário Verde, Vergílio Ferreira, Luís Miguel Nava, Nuno Júdice, José Luís Peixoto, José Saramago e Mario de Sá Carneiro, de que este ano se celebra o centenário de morte (26/ abril/ 1916).

O problema de se destacarem alguns dos talentos que compõem uma antologia está, como é sabido, em não se poder citar a todos, igualmente merecedores de destaque, e que dela fazem parte. Fica, assim, o livro para a descoberta do leitor. Dentre tantos e bons, reproduzo, enfim, abaixo, os versos de Camões que nos levam a pensar na (a)ventura do humano, como convite para a leitura:

[...] Enfim que, nesta incógnita espessura,

Deixámos pera sempre os companheiros

Que, em tal caminho e em tanta desventura,

Foram sempre conosco aventureiros.

Quão fácil é ao corpo a sepultura!

Quaisquer ondas do mar, quaisquer outeiros

Estranhos, assi mesmo como aos nossos,

Receberão de todo o llustre os ossos. [...] (p. 59) 


\section{Referências}

ROCHA, Clara Crabbé. A Caneta que Escreve e a que Prescreve; Doença e Medicina na Literatura Portuguesa. Antologia (Org.) Clara Crabbé Rocha e colaboração de Teresa Jorge Ferreira. Edição Babel, 2011.

NEMÉSIO, Vitorino. Portugal; A Terra e o Homem. Edição da Fundação Calouste Gulbekian, 1978.

PERRONE-MOISÉS, Leyla. Pessoa e a doença no Ocidente. Revista Via Atlântica, São Paulo n. 4, p. 94-105, out/ 2000.

SOARES, Nelson. "A Caneta que escreve e a que prescreve": História da literatura portuguesa aos olhos da Medicina. Revista Norte Médico. Portugal, v. 5, p.90-91, abril-junho, 2012. Disponível em (pdf):

<http://www.nortemedico.pt/publicacoes/?imr=433\&imc $=435 \mathrm{n} \& \mathrm{fmo}=$ pa\&publicacao $=$ 41\&edicao=779>. Acesso em 26/ maio 2016. 